(c) 2020 by «D. Rogachev NMRCPHOl»

Received 27.01.2020 Accepted 21.02.2020

Correspondence: Anjeline Dsouza, Manipal College of Nursing Manipal Academy of Higher Education, Manipal, India E-mail: anjeline.dOmanipal.edu

DOI: $10.24287 / 1726-1708-2020-19-3-12-16$

\title{
Description of health related quality of life of children and adolescents with hemophilia from India
}

\author{
A. Dsouza ${ }^{1}$, D. Nayak², A. Kurien³, M.S. Pai', B.S. Nayak ${ }^{1}$ \\ ${ }^{1}$ Manipal College of Nursing Manipal Academy of Higher Education, Manipal, India \\ 2TMA Pai Hospital, Udupi, Manipal Melaka Medical College, Manipal Academy of Higher Education, Manipal, \\ India \\ ${ }^{3}$ Manipal Melaka Medical College, Academy of Higher Education, Manipal, India \\ ${ }^{4}$ Manipal Academy of Higher Education, Manipal, India
}

\begin{abstract}
Hemophilia is a genetic disease that impairs quality of life due to its chronicity of nature where the individual will experience spontaneous bleeding or bleeding after an injury which requires frequent visits to the hospital for treatment. The objective of this study was to find the Health-related quality of life (HRQoL) of children and adolescents with moderate and severe hemophilia between 6 years and 16 years using the Haemo-QoL questionnaire. A prospective survey was carried out among 107 children and adolescents from two hemophilia treatment centers in Karnataka state. Approval was taken from the ethical committee. The data was analyzed using SPSS version 16.0. The mean age was $11.00 \pm 2.98$ years. Among the 107 participants, $89.70 \%$ had hemophilia A and $10.30 \%$ had hemophilia B. Moderate hemophilia was found among $54.20 \%$ participants and $45.80 \%$ had severe hemophilia. Overall, the HRQoL scores (55.41) were higher in the age group of 6-7 years compared to 8-12 years and $13-16$ years. The mean HRQoL in the domain of family were: $77.84 \pm 23.12$ among $6-7$ years, $66.00 \pm 17.34$ among the 8-12 years and $60.38 \pm 16.72$ among $13-16$ years. Children demonstrated poor HRQoL in the domains of family and friends. The results indicate a need for continuous monitoring of QoL to identify better treatment methods.
\end{abstract}

Key words: hemophilia, children, adolescents, Health related quality of life, Haemo-QoL, India

Dsouza A., et al. Pediatric Hematology/Oncology and Immunopathology. 2020; 19 (3): 12-16. DOI: 10.24287/1726-1708-2020-19-3-12-16

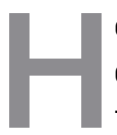

emophilia is an inherited, $\mathrm{X}$-linked chromosome disorder resulting in deficiencies of clotting factor VIII, or factor IX, which primarily affects males [1]. Based on the clotting factor activity level, hemophilia is categorized as severe $(<1 \mathrm{IU}$ $\mathrm{dL}^{-1}$ ), moderate (1-5 IU $\mathrm{dL}^{-1}$ ) and mild hemophilia (5-40 IU dL $\mathrm{dL}^{-1}$ [2]. A developing country like India has $10 \%$ of People with Hemophilia (PWH) when we compare with the global statistics [3]. As per the 2017 survey by World Federation of Hemophilia, only 18,966 PWH from India are diagnosed and registered [4]. In a country like India where the treatment is scare due to its cost and affordability by the individual/family affected, results in the chronicity of the problem such as joint bleeds. It is a vicious cycle, and a state of chronic condition develops where hemophilic arthritis is a major cause of morbidity in individuals with moderate and severe hemophilia [5]. Persons with hemophilia require continuous prophylactic treatment with factor concentrate to lead a better quality of life [6]. The assessment of the outcome of treatment of hemophilia is measured by the number of bleeding rates, joint status, physical functioning and healthrelated quality of life (HRQoL) [7].
QoL indicates the patient's perception about their life, goals, expectations and standards [8]. A chronic disease like hemophilia mostly affects HRQoL. HRQoL, measures an individual's perception about different components of wellbeing and function. This includes physical, emotional, mental, social and behavioral components [9]. HRQoL assessment is a popular, valid measure to assess the effect of care provided by health care members [10].

The majority of PWH do not have access to care in developing countries [3]. There are limited studies that report the $H R Q$ oL of PWH in developing countries like India, where the majority of individuals receive on demand factor replacement or episodic treatment after bleeding occurs. This study was conducted to assess the HRQoL among children and adolescents with moderate and severe hemophilia.

\section{MATERIALS AND METHODS}

The current research work was undertaken in two hemophilia centers (Manipal and Bengaluru) of Karnataka state in the period from February 2014 to January 2015. Participants for the study were children 
(between 6 to 12 years) and adolescents (between 13 to 16 years) who had moderate and severe hemophilia. Persons with mild hemophilia, with positive inhibitor status and on prophylaxis therapy were excluded. Children below 6 years were not included as the researcher found that it was difficult for them to read and comprehend questionnaire during pilot testing. To collect data on HRQoL from children between 6 to 9 years the researcher interviewed children along with their parents. Questionnaire was distributed to above 10 years of children and they filled it. Data was collected from 107 participants during a summer camp "Asha Kiran" conducted every year by Manipal Hemophilia Center and during annual general body meetings/annual clinic review.

The sociodemographic data collected were age in years, severity of hemophilia (moderate/severe), education, family history of hemophilia and age of diagnosis. The O.P. Aggarwal et al. socioeconomic status scale with 22 questions was administered to parents and based on this socioeconomic status was categorized as upper high ( $\geq 76$ ), high (61-75), upper middle (46-60), lower middle (31-45), poor (16-30) and very poor (15 and below) [11]. To assess QoL, the Haemo-QoL a standardized, validated selfreport questionnaire for children, was used. It has three versions for different age groups: version I for children of 4-7 years of age (21 items), version II for children of 8-12 years of age (64 items), and version III for children of $13-16$ years of age (77 items) [12].

Version I consists of 8 domains: "physical health" (4 items), "feeling" ( 3 items), "view of yourself" (2 items), "family" (4 items), "friends" (1 item), "other persons" (2 items), "sports and school" ( 3 items) and "treatment" (2 items). Physical health mainly focuses on joint mobility, fear of bleeds, pain in joints and difficulty in walking. For example, in the past four weeks my swellings hurt. Feeling sad about hemophilia, feeling lonely and worried about hemophilia were included in the domain of "feeling". "View of yourself" includes whether the child feels embarrassed due to hemophilia, comparison with other healthy boys and do they feel weak in group. Domain of "family" included questions regarding overprotection from mother and father, causing trouble/disturbance in the family due to hemophilia. Care and support from friends included in the domain of "friends". "Sports and school" mainly focuses on whether the child was able to involved in sports activities and had any difficulties in attending school.

Version II consisted of 10 domains with two additional domains i.e., "perceived support" and "dealing with hemophilia". Support from others were included in the area of perceived support. Version III
Table 1

Description of Haemo-QoL tools

\begin{tabular}{|c|c|c|c|c|}
\hline \multirow{2}{*}{ SI. No. } & \multirow{2}{*}{ Domains } & \multicolumn{3}{|c|}{$\begin{array}{c}\text { Number of items and (highest } \\
\text { possible score) }\end{array}$} \\
\hline & & $4-7$ yrs & $8-12$ yrs & $13-16$ yrs \\
\hline 1 & Physical health & $4(12)$ & 7 (35) & 7 (35) \\
\hline 2 & Feeling & $3(9)$ & $7(35)$ & $8(40)$ \\
\hline 3 & View of yourself & $2(6)$ & $9(45)$ & $10(50)$ \\
\hline 4 & Family & $4(12)$ & $5(25)$ & $8(40)$ \\
\hline 5 & Friends & $1(3)$ & $4(20)$ & $4(20)$ \\
\hline 6 & Other persons & $2(6)$ & $6(30)$ & $6(30)$ \\
\hline 7 & Sports and school & $3(9)$ & $8(40)$ & $9(45)$ \\
\hline 8 & Treatment & $2(6)$ & $7(35)$ & $8(40)$ \\
\hline 9 & Perceived support & - & $4(20)$ & $4(20)$ \\
\hline 10 & $\begin{array}{l}\text { Dealing with } \\
\text { hemophilia }\end{array}$ & - & $7(35)$ & $7(35)$ \\
\hline 11 & Future & - & - & $4(20)$ \\
\hline 12 & Relationships & - & - & $2(10)$ \\
\hline \multicolumn{2}{|c|}{ Total items } & 21 (63) & $64(320)$ & 77 (385) \\
\hline
\end{tabular}

consisted of 11 subscales, where the domain of "future" and "relationship" is included.As the domain relationship was not applicable to our culture this area was not included in the present study. In the Haemo-QoL questionnaires a higher total score indicates a poorer quality of life and because each version had a different metric and a different number of subscales, the total scores were transformed into a scale from 0 to 100 thus allowing the groups to be compared [13, 14]. High values indicate high impairments in HRQoL (table 1).

Permission was obtained from the authors to use Haemo-QoL questionnaires. Psychometric testing involved the examination of validity and reliability. All the tools have got sufficient discriminant and convergent validity. The reliability score for Haemo-QoL was 0.70 .

\section{Ethical considerations}

Study protocol was approved by the Institutional Ethics Committee (IEC 152/2013) of Kasturba Hospital, Manipal. Participant information sheet was given to all participants. Confidentiality of the data was assured by the researcher. Consent from parents and assent from participants were obtained before conducting the study.

The statistical analysis was done by using the SPSS version 16.0. Kolmogorov-Smironov test was performed to test the normality of the data. Descriptive data were shown as frequency distribution or mean and standard deviation.

\section{RESULTS}

The study included 107 children and adolescents with moderate and severe hemophilia. 
Table 2

Sample characteristics of children and adolescents with hemophilia $(n=107)$

\begin{tabular}{|c|c|c|c|}
\hline $\begin{array}{l}\text { Sl. } \\
\text { No. }\end{array}$ & Characteristics & Frequency & Percentage \\
\hline 1 & $\begin{array}{c}\text { Age in years: } \\
6-7 \\
8-12 \\
13-16 \\
\end{array}$ & $\begin{array}{c}11.00 \pm 2.98 \\
23 \\
44 \\
40 \\
\end{array}$ & $\begin{array}{l}21.50 \\
41.10 \\
37.40\end{array}$ \\
\hline 2 & $\begin{array}{c}\text { Type of hemophilia: } \\
\text { hemophilia A } \\
\text { hemophilia B }\end{array}$ & $\begin{array}{l}96 \\
11\end{array}$ & $\begin{array}{l}89.70 \\
10.30\end{array}$ \\
\hline 3 & $\begin{array}{c}\text { Severity of hemophilia: } \\
\text { moderate } \\
\text { severe }\end{array}$ & $\begin{array}{l}90 \\
49 \\
\end{array}$ & $\begin{array}{l}54.20 \\
45.80 \\
\end{array}$ \\
\hline 4 & $\begin{array}{c}\text { Education: } \\
\text { not going to school } \\
\text { anganawadi/nursery } \\
\text { primary school } \\
\text { higher primary } \\
\text { high school } \\
\text { PUC }\end{array}$ & $\begin{array}{c}2 \\
7 \\
38 \\
31 \\
25 \\
04\end{array}$ & $\begin{array}{c}1.90 \\
6.50 \\
35.50 \\
29.00 \\
23.40 \\
3.70 \\
\end{array}$ \\
\hline 5 & $\begin{array}{c}\text { Socioeconomic status: } \\
\text { very poor }(\leq 15) \\
\text { poor }(16-30) \\
\text { lower middle }(31-45) \\
\text { upper middle }(46-60) \\
\text { high }(61-75) \\
\text { upper high }(\geq 76) \\
\end{array}$ & $\begin{array}{l}- \\
20 \\
72 \\
15 \\
- \\
-\end{array}$ & $\begin{array}{c}- \\
18.70 \\
67.3 \\
14.0 \\
- \\
- \\
\end{array}$ \\
\hline 6 & $\begin{array}{c}\text { Age at diagnosis: } \\
\text { within } 1 \mathrm{yr} \\
>1-2 \mathrm{yr} \\
>2-4 \mathrm{yr} \\
>4-10 \mathrm{yr} \\
>10-15 \mathrm{yr}\end{array}$ & $\begin{array}{l}65 \\
21 \\
12 \\
7 \\
2 \\
\end{array}$ & $\begin{array}{l}60.70 \\
19.60 \\
11.20 \\
6.50 \\
1.90 \\
\end{array}$ \\
\hline 7 & $\begin{array}{c}\text { Family history of hemophilia: } \\
\text { yes } \\
\text { no }\end{array}$ & $\begin{array}{l}51 \\
56\end{array}$ & $\begin{array}{l}47.70 \\
52.30\end{array}$ \\
\hline
\end{tabular}

Table 3

Mean, standard deviation of quality of life scores among children and adolescents (Mean \pm SD)

\begin{tabular}{|c|c|c|c|c|}
\hline \multirow[b]{2}{*}{ Characteristics } & \multicolumn{3}{|c|}{ Age group } & \multirow{2}{*}{ 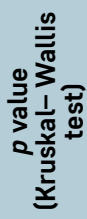 } \\
\hline & 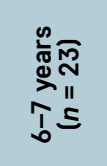 & 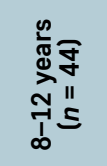 & 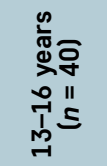 & \\
\hline Physical health & $\begin{array}{c}49.43 \pm \\
28.99\end{array}$ & $\begin{array}{c}49.20 \pm \\
19.63\end{array}$ & $\begin{array}{c}47.05 \pm \\
23.06\end{array}$ & 0.978 \\
\hline Feeling & $\begin{array}{c}50.75 \pm \\
25.44\end{array}$ & $\begin{array}{c}49.12 \pm \\
20.17\end{array}$ & $\begin{array}{c}44.94 \pm \\
23.87\end{array}$ & 0.853 \\
\hline View of yourself & $\begin{array}{c}42.04 \pm \\
32.17\end{array}$ & $\begin{array}{c}48.76 \pm \\
12.83\end{array}$ & $\begin{array}{c}41.11 \pm \\
13.03\end{array}$ & 0.550 \\
\hline Family & $\begin{array}{c}77.84 \pm \\
23.12\end{array}$ & $\begin{array}{c}66.00 \pm \\
17.34\end{array}$ & $\begin{array}{c}60.38 \pm \\
16.72\end{array}$ & $0.033^{*}$ \\
\hline Friends & $\begin{array}{c}50.00 \pm \\
35.35\end{array}$ & $\begin{array}{c}66.00 \pm \\
17.34\end{array}$ & $\begin{array}{c}57.53 \pm \\
25.69\end{array}$ & 0.058 \\
\hline Other persons & $\begin{array}{c}70.45 \pm \\
10.87\end{array}$ & $\begin{array}{c}34.72 \pm \\
18.11\end{array}$ & $\begin{array}{c}33.33 \pm \\
19.96\end{array}$ & $0.001^{*}$ \\
\hline Sports and school & $\begin{array}{l}58.0 \pm \\
16.06\end{array}$ & $\begin{array}{c}63.12 \pm \\
15.99\end{array}$ & $\begin{array}{c}52.69 \pm \\
14.28\end{array}$ & $0.014^{*}$ \\
\hline Treatment & $\begin{array}{l}50.0 \pm \\
40.09\end{array}$ & $\begin{array}{c}36.19 \pm \\
18.98\end{array}$ & $\begin{array}{c}41.45 \pm \\
16.46\end{array}$ & 0.203 \\
\hline Perceived support & - & $\begin{array}{c}51.52 \pm \\
27.34\end{array}$ & $\begin{array}{c}49.63 \pm \\
22.18\end{array}$ & 0.514 \\
\hline Dealing with hemophilia & - & $\begin{array}{c}40.31 \pm \\
21.70\end{array}$ & $\begin{array}{c}49.47 \pm \\
26.84\end{array}$ & 0.083 \\
\hline Future & - & - & $\begin{array}{c}46.69 \pm \\
15.01\end{array}$ & - \\
\hline Total score $(0-100)$ & $\begin{array}{c}55.41 \pm \\
14.48\end{array}$ & $\begin{array}{c}49.62 \pm \\
10.12\end{array}$ & $\begin{array}{c}47.62 \pm \\
9.97\end{array}$ & - \\
\hline
\end{tabular}

Note. Mann-Whitney $U$ test was done for perceived support and dealing with hemophilia as it is applicable for group II and III only; " - significant.
The mean age was $11.00 \pm 2.98$ years, most $(41.10 \%)$ were in the age group of $8-12$ years. The majority $(89.70 \%)$ were diagnosed with hemophilia $\mathrm{A}$, and $54.20 \%$ were diagnosed with moderate hemophilia. The majority of participants reported that there was no family history of hemophilia. Sample characteristics are described in table 2.

It was found that "family" (77.84), "other persons" (70.45), and "sports" (58.0) were major concerns compared to other areas in the age group of 6-7 years. HRQoL in the area of "family", "friends", "sports" and "school" were much impaired compared to other areas such as "treatment" and "dealing with hemophilia" in 8 to 12 years of children. It was observed that children of 13-16 years had a poor quality of life in the area "family" (60.30) and, "friends" (57.53) compared to the other areas (as high scores demonstrate worse $\mathrm{HRQ} \mathrm{oL}$ ). The mean scores are presented in table 3. It was found that in the age group of 8-12 years, there was significant difference in the domain of "feeling" $(p=0.001)$, "view" ( $p=0.45)$ and "other persons" $(p=0.044)$. In the age group of 13-16 years there was significant difference in the domain of "physical health" $(p=0.033)$ and "view" $(p=0.030)$.

HRQoL was compared according to the severity of children with severe and moderate hemophilia by using the Haemo-QoL scores in the age group of 6 to 12 years and $13-16$ years (figures 1,2 ). It was found that in the age group of 13-16years in all domains severe hemophiliacs had poor quality of life compared to moderate hemophiliacs except dealing with hemophilia.

\section{DISCUSSION}

The objective of the study was to assess HRQoL in children and adolescents with hemophilia who were visiting two hemophilia treatment centers in Karnataka state, India.

The results showed that the dimension of "family and other persons" was highly impaired in children between 6 to 7 years. We also found that the quality of life was impaired in the area of "family and friends" compared to "physical health" and "feeling" in children between 8 and 12 years. Similar findings of HRQoL were reported by M.Y. Taha, M.K. Hassan in children and adolescents in Basra, Southern Iraq. The component of 'family' was impaired among younger children; children aged 8 to 12 years were mainly impaired in the dimension of "sports", and adolescents in "perceived support". QoL mainly depends on the severity of hemophilia; patients with severe hemophilia have a poor quality of life compared to patients with mild hemophilia [14]. Tantawy also studied the HRQoL of 60 severe hemophilic children and adolescents 


\section{Figure 1}

Mean value of Haemo-QoL dimension based on severity of hemophilia among children aged 8 to 12 years

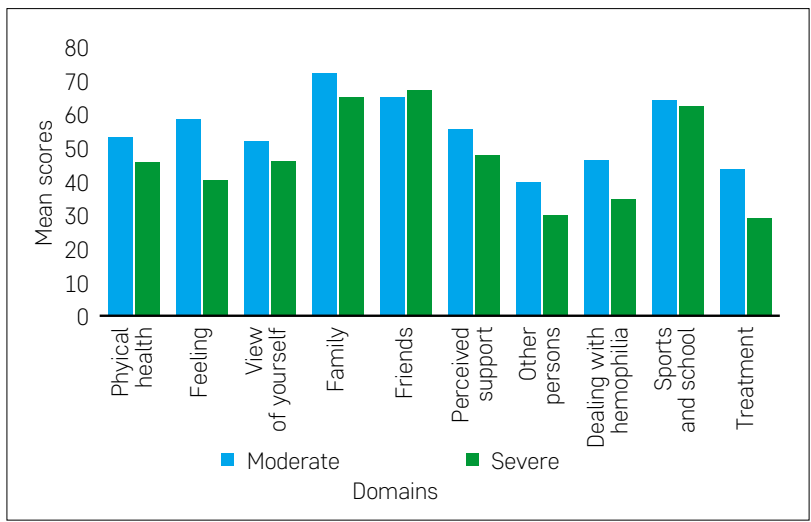

from Egypt by using Hemo-QoL. The scores of HRQoL were found to be widely above 50 for all subscales. It was highly significant in the dimension of "physical health" and "family" and "treatment" in different age groups. Among 8-12 years and 13-16 years group the dimension "physical health" was impaired. The dimension of family was impaired for the adolescents and the youngest group had highly impaired scores concerning treatment [15].

In our study we found that in group III (13 to16 years) the areas of "family" and "friends" were not satisfactory, similar to the previous findings of St. Louis et al. [16] who reported, slightly worse HRQoL in the domains "physical functioning" and "pain" among Canadian youth with hemophilia. Ferreira et al reported that "sports and leisure" and "physical health" were the most impaired dimensions and the dimension "relationship and partners" was the least impaired among hemophiliac adults using the haem-A-QoL questionnaire [17]. Miners et al evaluated HR-QoL using the EQ-5D questionnaire among 249 adults with severe hemophilia, and reported lower levels of HR-QoL [18].

Comparison of HRQoL based on severity of hemophilia showed higher impairment among severe hemophiliacs in the age group of 13-16 years. This is similar to the study in the Southern Iraq by M.Y. Taha, M.K. Hassan who reported that compared with individuals with moderate/mild hemophilia, children and adolescents with severe hemophilia have poor HRQoL [14].

The study included a wide range of age group from 6 to 16 years, where the HRQoL scores are mostly influenced by age. Children showed a poor quality

\section{Figure 2}

Mean value of Haemo-QoL dimension based on severity of hemophilia among children aged 13 to 16 years

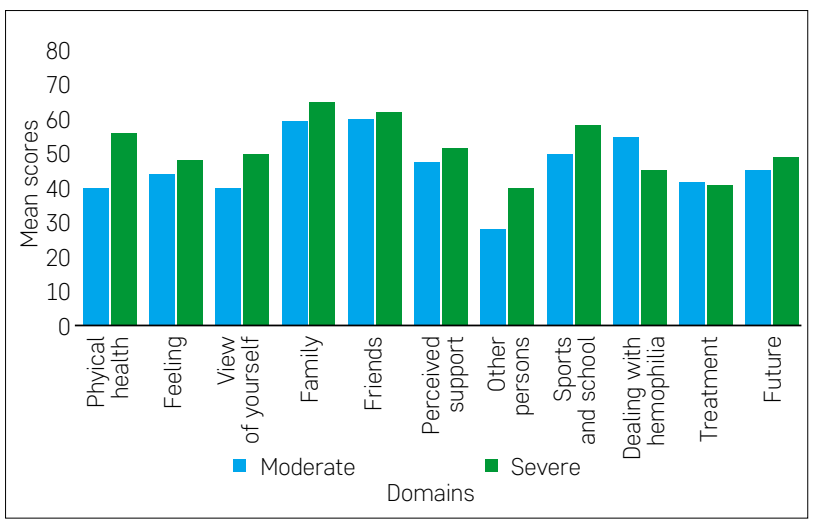

of life in the domain "family" which may be due to overprotection by the parents to avoid injuries due to contact sports as all participants in this study were treated with on demand factor replacement therapy.

\section{CONCLUSION}

Children and adolescents with hemophilia reported lower levels of quality of life in several areas. The results indicate a need for a continuous monitoring of QoL to identify better treatment methods. Comprehensive care and factor replacement therapy is required to improve the $\mathrm{QoL}$ of children and adolescents.

\section{ACKNOWLEDGEMENTS}

We thank Dr. Sylvia Von Mackenson, Professor of Psychology, Department of Medical Psychology, University Medical Centre Hamburg-Eppendorf, Hamburg,Germany for permitting us to use the tool and also guiding in interpretation of scores. We thank all children and adolescents with hemophilia who participated in the study. We thank all members of hemophilia society in Manipal and Bengaluru for their support in conducting this study.

\section{FUNDING}

Not specified.

\section{CONFLICTS OF INTEREST}

The authors have no conflicts of interest to disclose. This paper was produced as a part of the Project titled "Identification, Diagnosis, Education, and Empowerment for Action" of the people with bleeding disorders in South India (IDEEA) funded by Novo Nordisk Hemophilia Foundation, Zurich, Switzerland. The funders had no role in the study design, data collection and analysis, decision to publish or preparation of the manuscript. 


\section{References}

1. Franchini M., Mannucci P.M. Hemophilia $A$ in the third millennium. Blood Rev 2013; 27 (4): 179-84. DOI: 10.1016/j. blre.2013.06.002

2. Broderick C.R., Herbert R.D., Latimer J., Curtin J.A., Selvadurai H.C. The effect of an exercise intervention on aerobic fitness, strength and quality of life in children with haemophilia (ACTRN012605000224628). BMC Hematology 2006; 6 (1): 2. DOI: 10.1186/1471-2326-6-2

3. Bansal D., Totadri S. Comprehensive hemophilia management in India-Miles to go before we sleep. Indian Pediatr 2018; 55: 559-60.

4. World federation of Hemophilia (2018) Report on annual global survey 2017. World federation of Hemophilia, Montreal. Available from: http://www1. wfh.org/publications/files/pdf-1714. pdf

5. Boehlen F., Graft L., Berntorp E. Outcome measures in haemophilia: A systematic review. Eur J Haematol Suppl 2014; 76: 2-15. DOl: 10.1111/ ejh.12369

6. Von Mackensen S., Harrington C., Tuddenham E., Littley A., Will A., Fareh M., et al. The impact of sport on health status, psychological well-being and physical performance of adults with haemophilia. Haemophilia 2016; 22 (4): 521-30. DOI: 10.1111/hae.12912

7. Van den Berg H.M., Feldman B.M., Fischer K., Blanchette V., Poonnoose P., Srivastava A. Assessments of outcome in haemophilia - what is the added value of QoL tools? Haemophilia 2015; 21 (4): 430-5. DOl: 10.1111/ hae. 12731
8. Development of the World Health Organization WHOQOL-BREF Quality of Life Assessment. The WHOQOL Group. Psychol med 1998; 28 (3): 551-8. DOI: 10.1017/S0033291798006667

9. Rentz A., Flood E., Altisent C., Bullinger M., Klamroth R., Garrido R.P., et al.; Members of the HAEMO-QoL-A Steering Committee. Cross-cultural development and psychometric evaluation of a patient-reported health-related quality of life questionnaire for adults with haemophilia. Haemophilia 2008; 14 (5): 1023-34. DOI: 10.1111/j.13652516.2008.01812.x

10. Oladapo A.O., Epstein J.D., Williams E., Ito D., Gringeri A., Valentino L.A. Health-related quality of life assessment in haemophilia patients on prophylaxis therapy: a systematic review of results from prospective clinical trials. Haemophilia 2015; 21 (5): e344-58. DOl: 10.1111/hae.12759

11. Aggarwal O.P., Bhasin S.K., Sharma A.K., Chhabra P., Aggarwal K., Rajoura O.P. A new instrument (scale) for measuring the socioeconomic status of a family: Preliminary study. Indian J Community Med 2005; 30 (4): 111-4.

12. Bullinger M.V., Von Mackensen S., Fischer K., Khair K., Petersen C., RavensSieberer U., et al. Pilot testing of the 'Haemo-QoL'quality of life questionnaire for haemophiliac children in six European countries. Haemophilia 2002; 8 Suppl 2: 47-54. DOI: 10.1046/ j.1351-8216.2001.114.doc.x

13. Von Mackensen S., Bullinger M.; Haemo-QoL Group. Development and testing of an instrument to assess the Quality of Life of Children with
Haemophilia in Europe (Haemo-QoL). Haemophilia 2004; 10: 17-25. DOI: 10.1111/j.1355-0691.2004.00875.x

14. Taha M.Y., Hassan M.K. Health-related quality of life in children and adolescents with hemophilia in Basra, Southern Iraq. J Pediatr Hematol Oncol 2014; 36 (3): 179-84. DOI: 10.1097/ MPH.0000000000000117

15. Tantawy A.A., Mackensen S.V., El-Laboudy M.A., Labib J.H., Moftah F., El-Telbany M.A., et al. Health-related quality of life in Egyptian children and adolescents with hemophilia A. Pediatr Hematol Oncol 2011; 28 (3): 222-9. DOI: 10.3109/08880018.2010.535116

16. St-Louis J., Urajnik D.J., Menard F., Cloutier S., Klaassen R.J., Ritchie B., et al. Generic and disease specific quality of life among youth and young men with hemophilia in Canada. BMC Hematol 2016; 16: 13. DOI 10.1186/ s12878-016-0052-x

17. Ferreira A.A., Leite I.C., BustamanteTeixeira M.T., Correa C.S., da Cruz D.T., Rodrigues Dde 0., et al. Health-related quality of life in hemophilia: results of the Hemophilia-Specific Quality of Life Index (Haem-a-Qol) at a Brazilian blood center. Rev Bras Hematol Hemoter 2013; 35(5): 314-8. DOl: 10.5581/1516-8484.20130108

18. Minners A.H., Sabin C.A., Tolley K.H., Jenkinson C., Kind P., Lee C.A. Assessing health-related quality-of-life in individuals with haemophilia. Haemophilia 1999; 5: 378-85. DOI: 10.1046/j.1365-2516.1999.00347.x 